\title{
Case of tumoral calcinosis on images: a rare clinicopathological entity
}

\author{
Harpreet Singh, ${ }^{1}$ Richa Handa, ${ }^{2}$ Zeeshan Arshad, ${ }^{2}$ Eric G Hoover ${ }^{3}$
}

${ }^{1}$ Internal Medicine (Core Faculty), Henry Ford Allegiance Health Hospital, Jackson, Michigan, USA

${ }^{2}$ Resident, Allegiance Health, Jackson, Michigan, USA ${ }^{3}$ Radiology, Allegiance Health, Jackson, Michigan, USA

\section{Correspondence to} Dr. Harpreet Singh, harpreet91@gmail.com

Accepted 11 October 2017
CrossMark

\section{To cite: Singh $\mathrm{H}$, Handa $\mathrm{R}$} Arshad Z, et al. BMJ Case Rep Published Online First: [please include Day Month Year]. doi:10.1136/bcr-2017 222065

\section{DESCRIPTION}

We are presenting a case of tumoral calcinosis (TC) diagnosed on histopathology with characteristic X-ray, CT and MRI images. We acknowledge that although radiological and pathological descriptions are suggested as diagnostic criteria, mostly the term TC is saved for the condition caused by hereditary metabolic dysfunction of phosphate regulation associated with massive periarticular masses. Our patient had a normal

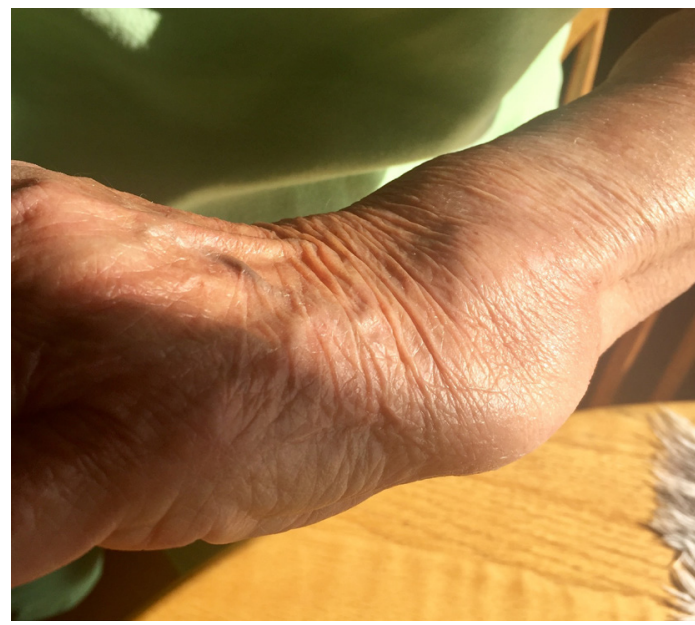

Figure 1 Patient's picture showing swelling on the left wrist.

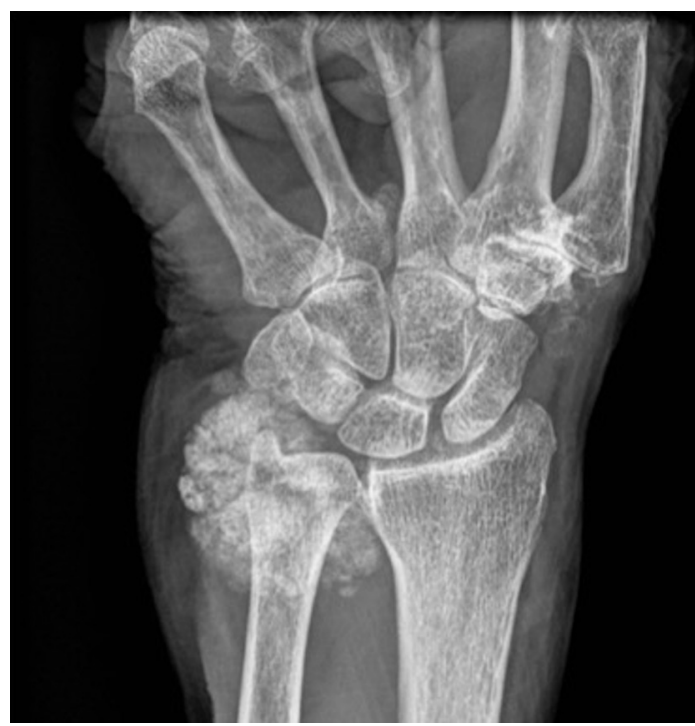

Figure 2 X-ray of left wrist showed large cloud-like calcified periarticular mass in the ulnar aspect of the left wrist at the level of the ulnar head characteristic of tumoral calcinosis. phosphate. On review of literature, normophosphatemic TC has also been described. ${ }^{1}$

An 81-year-old Caucasian woman presented with left wrist pain and swelling, which first began approximately 3-4 years ago. As per patient, she saw her physician regarding this 1 year ago and was diagnosed with gout. Physical examination showed $4 \times 3 \mathrm{~cm}$ left-sided volar ulnar wrist mass (figure 1 ).

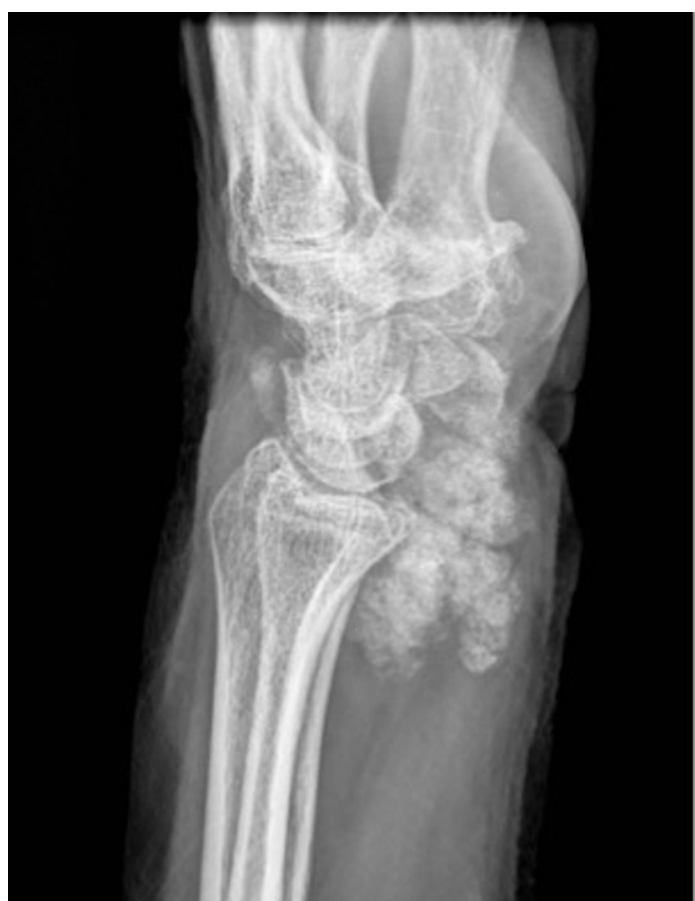

Figure 3 Lateral view on X-ray.

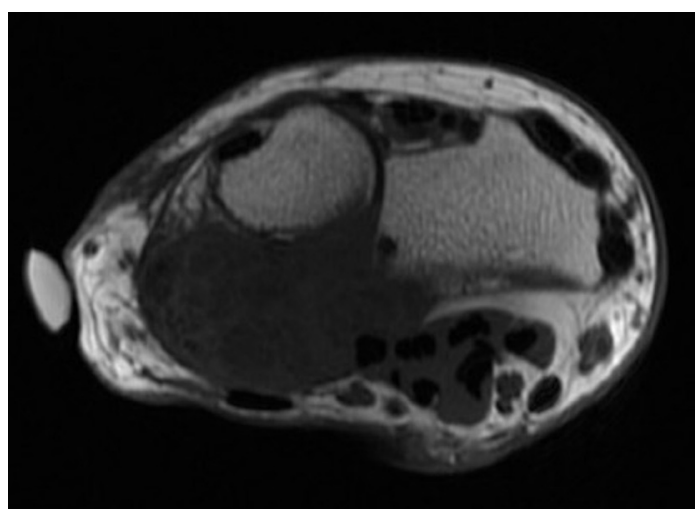

Figure 4 MRI showing axial T1-weighted images of the wrist demonstrating an inhomogeneous predominantly hypointense mass at the volar surface of the distal radioulnar joint with multiple foci of darker signal. 


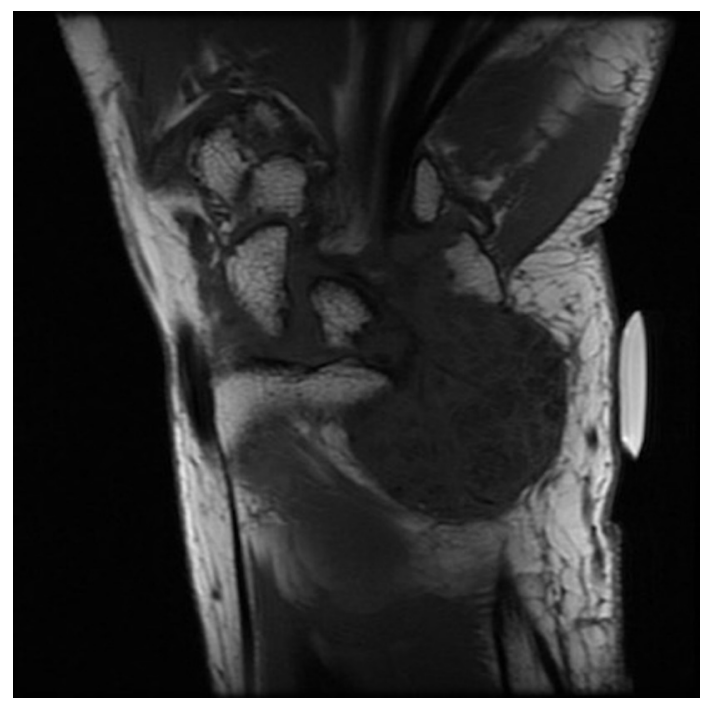

Figure 5 MRI without contrast showing coronal T1-weighted images of the wrist demonstrating an inhomogeneous predominantly hypointense mass at the volar surface of the distal radioulnar joint with multiple foci of darker signal.

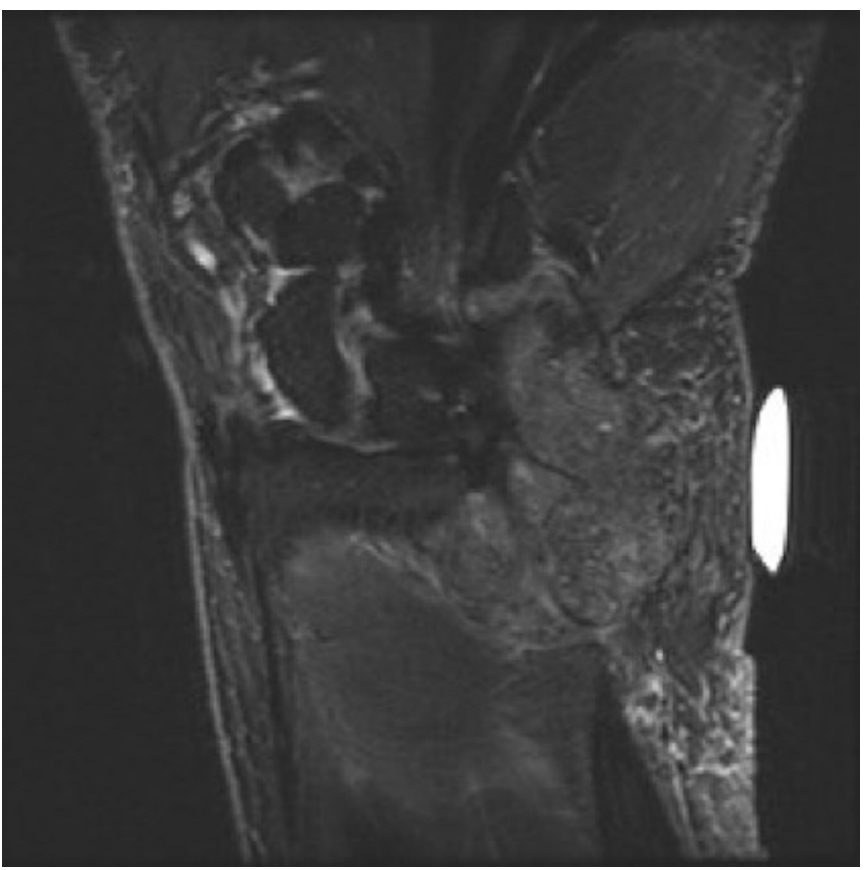

Figure 6 MRI left wrist with corresponding coronal T2 fat-saturated image also shows a predominantly inhomogeneous hypointense mass containing multiple smaller foci of darker signal.

The patient's vital signs and rest of the examination were within normal limits. No history of trauma reported. Labs: serum creatinine $0.72 \mathrm{mg} / \mathrm{dL}$, Vitamin D 25 was $20 \mathrm{ng} / \mathrm{mL}$. Para thyroid hormone (PTH) was not ordered as calcium was normal $(8.5 \mathrm{mg} /$ $\mathrm{dL}$ ). The patient did not report family history of TC so GALNT3 was not ordered. Connective tissue diseases were ruled out with negative rheumatoid factor (RF), anti nuclear antibody (ANA), cyclic Citrullinated peptide (CCP) and erythrocyte sedimentation rate (ESR). Single site ruled out calcinosis universalis and calcinosis circumscripta.

Calcific tendonitis was not thought because of non-involvement of tendon.

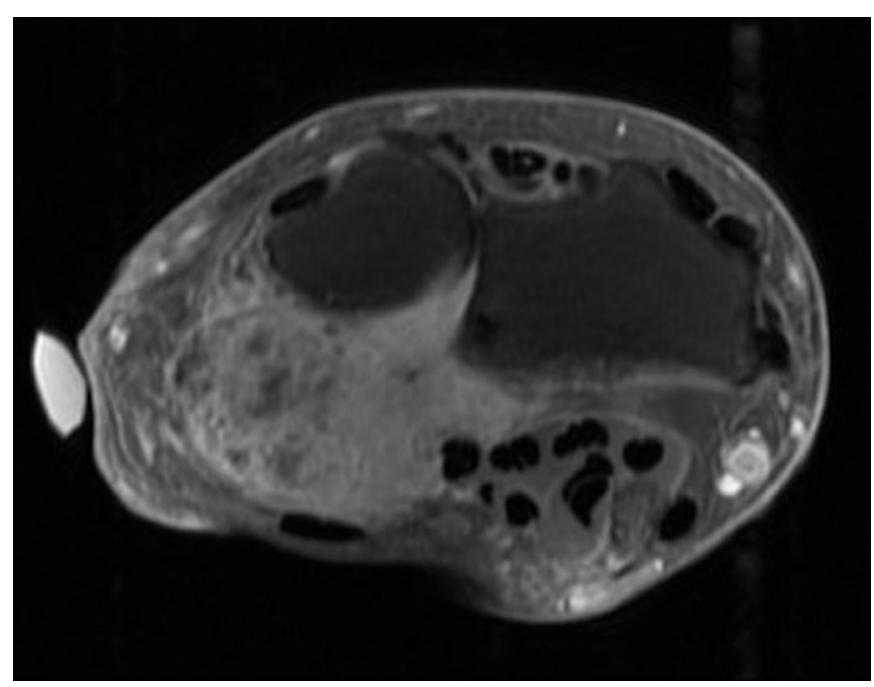

Figure 7 MRI left wrist axial section after intravenous contrast, the mass demonstrates mild diffuse heterogeneous enhancement with several foci of non-enhancement.

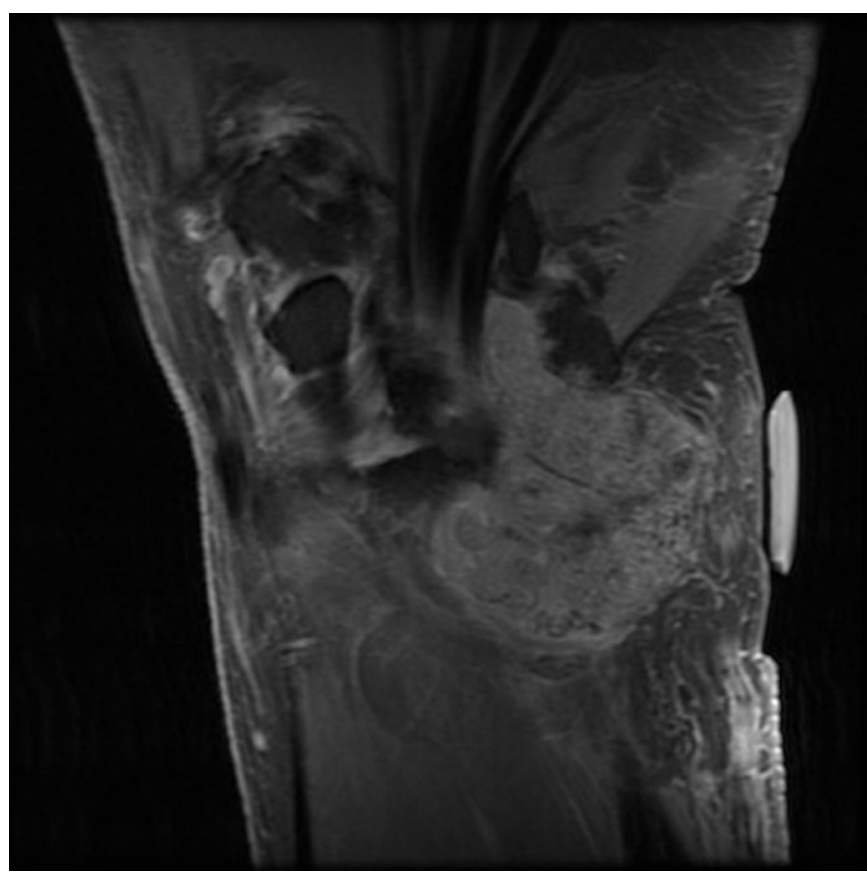

Figure 8 MRI left wrist coronal section after intravenous contrast, the mass demonstrates mild diffuse heterogeneous enhancement with several foci of non-enhancement.

Synovial osteochondromatosis, synovial sarcoma, myositis ossificans, calcific myonecrosis and tophaceous gout were ruled out by imaging and histopathology.

X-ray of the left wrist showed large cloud-like calcified periarticular mass in the ulnar aspect of the left wrist at the level of the ulnar head (figures 2 and 3). Based on X-rays, surgeons requested MRI. Axial and coronal T1-weighted images of the wrist demonstrated an inhomogeneous predominantly hypointense mass at the volar surface of the distal radioulnar joint with multiple foci of darker signal (figures 4 and 5). Corresponding coronal T2 fat-saturated image also showed a predominantly inhomogeneous hypointense mass containing multiple smaller foci of darker signal (figure 6). In gout, T2-weighted coronal MRI of the wrist demonstrates 


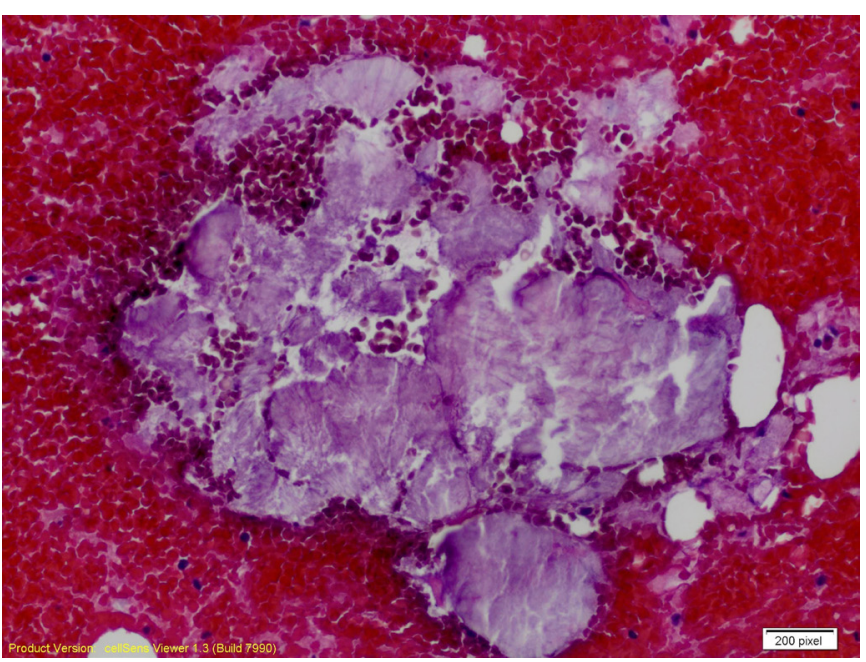

Figure 9 Ultrasound-guided biopsy was positive for acellular amorphous crystalline material and accompanying blood clot suggestive of tumoral calcinosis on pathology.

that the tophi are primarily hyperintense in signal, with some foci of intermediate signal also observed. ${ }^{1}$ After intravenous contrast, the mass demonstrated mild diffuse heterogeneous enhancement with several foci of non-enhancement (figures 7 and 8 ). Ultrasound-guided biopsy was positive for acellular amorphous crystalline material and accompanying blood clot, suggestive of TC on pathology (figure 9).

Biopsy was positive for acellular amorphous crystalline material with multinucleate giant cells and calcium granules diagnostic of TC. The characteristic appearances described by Olsen and Chew in their article were seen in the patient. ${ }^{2}$

Surgical options were considered but were not necessary other than for aesthetic reasons. On 1-year follow-up, no increase was seen in the swelling or pain.

\section{Learning points}

- Tumoral calcinosis (TC) is an uncommon benign condition characterised by solitary or multiple painless, periarticular masses composed of calcium salts. The radiological appearance is characteristic, and radiologists have an important role in diagnosis.

- Before diagnosing the patient with TC, dystrophic and metabolic calcification should be ruled out. The disease continues to remain a diagnostic challenge and the role of radiologist is important to avoid unnecessary medical and surgical workup. Patients with small lesions can be monitored without any medical and surgical management.

- Before surgical intervention, medical management including phosphate depletion through dietary restriction should be tried in patients with TC.

Contributors $\mathrm{RH}$ wrote the case and took patients and IRB's permission to submit the case. ZA helped $\mathrm{RH}$ with the case. EGH read the images as a radiologist and helped with writing on the case. HS is the corresponding author and prepared the case for submission.

Competing interests None declared.

\section{Patient consent Obtained.}

Provenance and peer review Not commissioned; externally peer reviewed.

(c) BMJ Publishing Group Ltd (unless otherwise stated in the text of the article) 2017. All rights reserved. No commercial use is permitted unless otherwise expressly granted.

\section{REFERENCES}

1 Smack D, Norton SA, Fitzpatrick JE. Proposal for a pathogenesis-based classification of tumoral calcinosis. Int J Dermatol 1996:35:265-71.

2 Olsen KM, Chew FS. Tumoral calcinosis: pearls, polemics, and alternative possibilities. Radiographics 2006;26:871-85.

Copyright 2017 BMJ Publishing Group. All rights reserved. For permission to reuse any of this content visit

http://group.bmj.com/group/rights-licensing/permissions.

BMJ Case Report Fellows may re-use this article for personal use and teaching without any further permission.

Become a Fellow of BMJ Case Reports today and you can:

- Submit as many cases as you like

- Enjoy fast sympathetic peer review and rapid publication of accepted articles

- Access all the published articles

- Re-use any of the published material for personal use and teaching without further permission

For information on Institutional Fellowships contact consortiasales@bmjgroup.com

Visit casereports.bmj.com for more articles like this and to become a Fellow 